\title{
How do Procurement and Separation relate with Performance Management System among Employees? Testing the Mediating role of ICT Adoption
}

\author{
Abubakar Allumi Nura, Nor Hasni Osman \\ Universiti Utara Malaysia, Malaysia \\ nallumi@yahoo.com
}

\begin{abstract}
This study is aimed at revealing how performance management system (PMS) relates to procurement and separation among employees in an organization. Several researches have been embarked upon in determining how one or two human resource management (HRM) practice (s) influence employee performance, however, an approach to studying the mediating effect of ICT adoption between procurement and separation and performance management system is still begging for rigorous academic attention. To reduce this widely created gap, the paper aimed at determining whether the procurement and separation are correlated to performance management system. The results however obtained through SmartPLS confirmed that there is full mediation effect of ICT adoption on one relationship and a partial mediation effect on the other.
\end{abstract}

Keywords: Performance management System, procurement, separation, ICT adoption, Nigeria.

\section{Introduction}

Some decades ago, discuss on effective performance management system and its requirements has provided a momentum for new-fangled approaches to public sector management reforms. In spite of the changes that have resulted aimed to deal with some of the most terrible forms of scenarios such as the brain drain in Nigerian universities due to the personalized nature of rule in which leaders exercise unlimited power; to embezzlement of state resources and institutionalized corruption; to lack of regard to education among others, this paper wants to argue that little has been done with regards the internal factors that are so challenging in the context of organizations such as procurement and separation practices. And it is indeed the aggregate performance of organizations that is translated into state performance. The challenges are becoming enormous every day and the efficiency and effectiveness of employee performance management system is more susceptible and open to the elements of the risk of failure. In today's highly spirited world, where boundaries are tight or even dismissed and struggle for dominance is solid, organizations need not to be reminded to sky rocket their performances and go beyond, to be able to survive the ever growing forces of stiff competition and rivalry; they no longer need to be told that human asset is and remains the most priceless valuable asset.

Issue: The true state of affairs in the Nigerian universities revealed that, the universities are grossly underperforming, always struggling to survive the challenges of the environment, their employees are often complaining and revolting against the management policies, there is a very alarming situation of brain drain due to un ceremonious separation of employees and etc. Hence the need for effective human resource management, with prominence on accountability and responsiveness to employee needs, a system that will serve as an antidote to the deteriorating state of education in the country is very paramount. The hurried development of the internet in the recent years has remarkably boosted the execution and relevance of electronic human resource management (e-HRM). Surveys conducted by HR consultants established that virtually all the organizations adopting e-HRM are continually increasing (e.g. Cedar, 2005). Similarly, a growing number of reports point out that e-HRM is becoming increasingly universal and may lead to remarkable changes. Accordingly, as Strohmeier (2007) pointed out, academic interest in e-HRM has increased and several works in HR-related journals keep appreciating (Stanton \& Covert, 2004; Townsend \& Bennett, 2003; Viswesvaran, 2003). Current challenges in Nigerian universities today demand a swift turn around to bring positive changes in Nigeria. It is necessary for the universities to quickly respond and 
reconcile between the quality of their recruitment and their ability to manage their employees to be able to slash separation to an appreciative level. That may help produce graduates that can address the dramatic economic and demographic conditions occurring in Nigerian society. The aim of this paper is to test the mediating effect of information and communication technology on the relationship between procurement and separation and performance management system among employees in the Nigerian universities.

\section{Literature Review}

Procurement and Performance Management: Procurement depicts a process through which an organization attracts individuals with appropriate job understanding, skills and ability; screened them based on merit and offer jobs to them that matches their skills and talents. Thus, whether an organization procures the desired quality workforce depends on appropriate procurement procedures and strategy that were put in place (Chang \& Chen, 2000). Performance Management as pointed out by Bernthal et al. (2003) starts with recruitment. An organization should be able to recruit, select and place the right people in the in the right place and at the right time. The opulence of recruiting from scratch the people that an organization believes will drive the organization to success is not an opportunity that is always available for grabs (Ishizaka \& Labib, 2011; Sodhi \& Lee, 2007). Again, it has been established in the literature that procurement exercise positively correlates with performance management (O’Neal, 2005; Tzafrir, 2006; Richard \& Johnson, 2001). Though it was not extensively clear as to which of aspects of procurement (recruitment, selection and placement) has the largest part positive impact (Huang, 2000). Borrowing the argument of Holton and Trot (2006), recruitment becomes a very important tool of guaranteeing effective individual performance management if appropriate procedures were put in place. More so, Tzafrir (2006) buttressed that organizations should adopt a viable recruitment strategy that will make the best use of their employees to ease the management of their performances. The above arguments clearly revealed that it has remain a sole university management responsibility to make sure that: the procurement procedure adopted can work, that the employee are carefully and appropriately selected; the employees can continue to be successful through support and adequate training; to be able to effectively manage employee performances.

Separation and performance management: This study defines employee separation as a situation where by employees un ceremoniously leaves their working places for other concerns due to lack of proper management. Employee separation is capable of affecting universities in either ways, positively and negatively (Meier \& Hicklin, 2008). If an organization succeeded in replacing the separated workforce with high performing, and capable employees with lots of talents, it could be said that separation is more or less a blessing than a curse. But when organization are left to battle with "brain drain" the repercussions would be very detrimental such as inefficiency and in effectiveness and overall decline in the quality of education and graduates as well. But, why are employees leaving public universities in Nigeria? Why is the brain draining instead of gaining? What would have been done to get things right? Those questions are without doubt important management questions begging for answers. Different studies have identified different possible reasons for employees separating from the public sector organizations for other concerns such as procurement (Kim, 2005; Moynihan \& Landuyt, 2008) and lack of viable technology (Yusoff et al., 2010).

\section{Methodology}

This paper employs a quantitative method of analysis and the respondents opinions are analyzed using SPSS and SmartPLS (Ringle, Wende \& Will, 2005).

Population and sample of the study: The population of the study comprises members of staff of five universities in North Western Nigeria which comprise the targeted population. The study adopted a disproportionate selection of 500 respondents out of which, only 218 supplied the required information to the topic of research, and the analysis was based on the 218 respondents.

Research Design: This study pursued a multimode survey strategy where different techniques of survey were undertaken such as the face to face questionnaire administration and an online survey. The focus was 
mainly on performance management system of employees, employee procurement and employee separation practices and the information and communication technology. The outlook of this study is a fact finding.

Instrumentation: One instrument was used to obtain data that was which was designed on a 5-point Likert scales to evaluate the different variables. The study adapted the items used from different sources.

Validity and Reliability: Composite reliability of the constructs was ascertained and the discriminant validity test was also undertaken. Table 1 displays the reliability analysis results.

Table 1: Displays the reliability analysis results

\begin{tabular}{llll}
\hline & AVE & Composite Reliability & R Square \\
\hline PMS & 0.55058 & 0.88019 & 0.45078 \\
PRCM & 0.67528 & 0.86147 & \\
SEPR & 0.66970 & 0.88998 & \\
ICT & 0.66755 & 0.85714 & 0.14809 \\
\hline
\end{tabular}

The Table 1 above indicates that the AVE of variables are: performance management $(\mathrm{PMS})=0.55$; procurement $(\mathrm{PRC})=0.67$; separation $(\mathrm{SEP})=0.66$ and ICT adoption $($ ICT $)=0.67$.

\section{Results}

Table 2 displays correlations of latent variables.

Table 2: Correlations of latent variables

\begin{tabular}{lllll}
\hline & PMS & PRCM & SEPR & ICT \\
\hline PMS & 0.742 & & & \\
PRCM & 0.567 & 0.822 & & \\
SEPR & 0.448 & 0.472 & 0.818 & \\
ICT & 0.307 & 0.238 & 0.332 & 0.817 \\
\hline
\end{tabular}

As shown in table 2 above, all the variables displayed a significant correlation at 0.1 levels thus, confirmed no problem of multicollinearity (Tabachnick \& Fidell, 1996). It was also revealed that the correlation of items alongside the constructs indicates an achievement of discriminant validity. Table 3 displays the result of test of hypotheses.

Table 3: Test of hypotheses

\begin{tabular}{lllllll}
\hline & $\begin{array}{l}\text { Original } \\
\text { Sample (0) }\end{array}$ & $\begin{array}{l}\text { Standard } \\
\text { (STERR) }\end{array}$ & Error & $\begin{array}{l}\text { T } \\
(\mid \mathbf{O} / \text { STERR } \mid)\end{array}$ & P-value & Decision \\
\hline PRCM -> PMS & 0.34 & 0.11 & 3.03 & 0.03 & Supported \\
PRCM - > ICT & 0.06 & 0.14 & 0.45 & 0.65 & not supported \\
SEPR -> PMS & -0.04 & 0.14 & 0.27 & 0.79 & not supported \\
SEPR -> ICT & 0.19 & 0.16 & 1.22 & 0.22 & supported \\
ICT-> PMS & 0.11 & 0.09 & 1.26 & 0.21 & supported \\
\hline
\end{tabular}

As shown in Table 3 above, three hypotheses were supported and two were not supported. The supported hypotheses indicate $\mathrm{p}$-value results that are $<0.5$. Table 4 that follows displays the effect size. 
Table 4: Displays the effect size

\begin{tabular}{lllll}
\hline Relationship & t-value & $\mathbf{p}$-value & $\mathbf{F}^{2}$ & Strength \\
\hline PRCM - > PMS & 3.03 & 0.03 & 0.13 & Medium \\
SEPR -> ICT & 1.22 & 0.22 & 0.02 & Small \\
ICT -> PMS & 1.26 & 0.21 & 0.02 & Small \\
\hline
\end{tabular}

Table 4 above shows the effect size of variables on DV and on the Mediator. As shown, the strength of $\mathrm{F}^{2}$ is medium in one relationship (PRCM-PMS) and small effect was reflected in two relationships (i.e. SEPR-ICT and ICT - PMS). Chin et al. (2003), buttressed that the fact that the $\mathrm{F}^{2}$ strength in some relationships is small; it does not relegate their statistical significance because they can cause change in a given relationship. The Figure 1 represents the study model.

\section{Figure 1: Study Model}

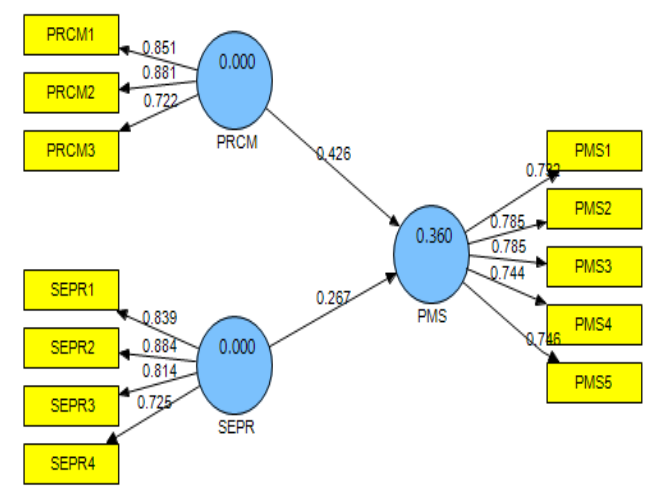

Test of Mediation: Unlike the test of mediation by Baron and Kenny (1986) this study employed a test of mediation technique that made provision for standard errors. The technique was undertaken by determining the path coefficients and the p-values of the dependent variable and the in dependent variable putting the mediator on hold and later in the presence of the mediator variable and the standard errors. Two different links were established i.e. $\boldsymbol{a} \boldsymbol{b}$ representing the path of independent variable to the mediator variable (X-Y), $\boldsymbol{b} \boldsymbol{c}$ representing the second link from the mediator variable to the dependent variable (M-Y).

The following formula that was adopted from Kock (2013) was used. i.e.

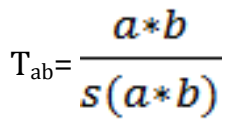

$\mathrm{a}=$ the value of relationship between independent variable and the mediator variable $\mathrm{b}=$ the value of the relationship between mediator variable and the dependent variable $S(\mathrm{a} * \mathrm{~b})=$ standard deviation of the "a" and "b" above 
The table 5 below displays the results of the mediating effect of ICT on the relationship between PRCM and SEPR and performance management system.

Table 5: Test of mediator ICT

\begin{tabular}{lll}
\hline PRCM & & SEPR \\
\hline$a^{*} b$ & 0.0024604 & 0.0919598 \\
$S$ & 0.0071762 & 0.0753877 \\
$T$ & 0.3 & 1.2 \\
\hline
\end{tabular}

The table 5 above displays the result of test of mediator ICT a t-value of 0.3 for PRCM (Procurement); 1.2 for SEPR (Separation). In the table above all the two variables are mediated. An indication of a full mediation is shown in one i.e. PRCM and a partial mediation in the other i.e. SEP with a $t$-value of 0.3 and 1.2 respectively which are all significant at one tail. The figure 2 below displays the mediating effect of ICT on the relationship between procurement and performance management system and separation and performance management system.

Figure 2: The mediating effect of ICT

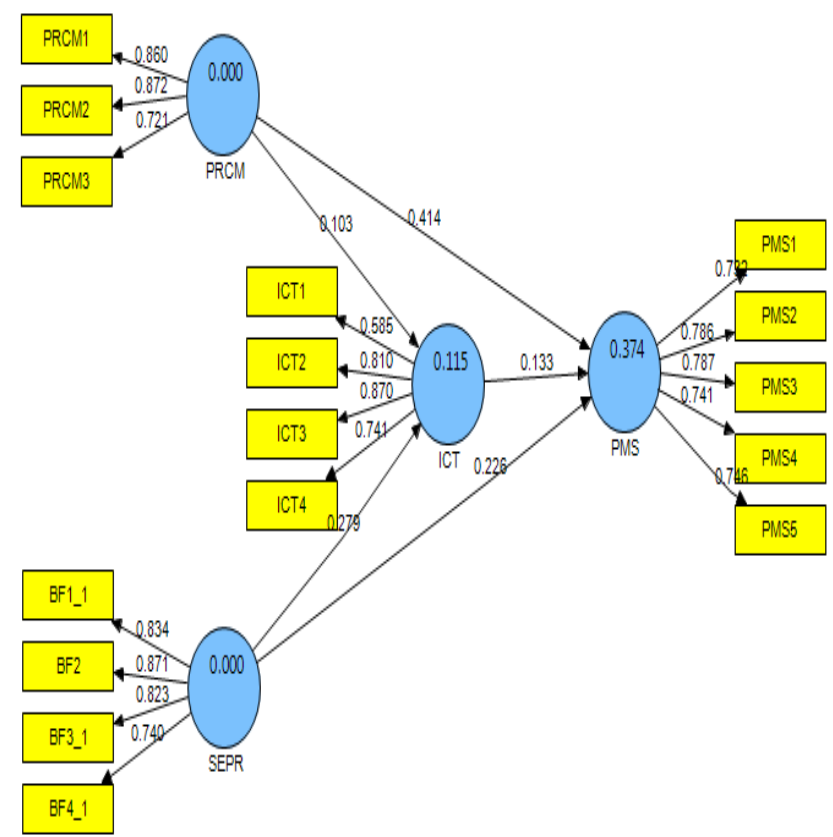

\section{Discussions}

The relationship between procurement and performance management system: This relationship is supported in this study since $\beta=0.11$; $t$-value $=3.03$ and $p$-value $=0.03$. The findings of this study concur 
with some previous studies that established that employee procurement results to stability and performance of employees and a pleasing result (Bowles et al., 2007; Den Hartog \& Verburg, 2004) and Heinen \& O'Neill (2004) further added that it cements cordial relationship between employer and employee.

The relationship between procurement and ICT adoption: This hypothesis is also not favored in this study because it indicates a $\beta$ value of $=0.14, t$-value $=0.45$, $p$-value $=0.65$. This finding perhaps contradicts a lot of literatures such as in Williams (2010), Yusoff et al. (2010), Handloglen (2009) and Hussain et al. (2007) who reported a significant positive relationship between ICT and procurement. This contradiction could be as a result of the fact that there are so many issues that constraint the implementation of e-recruitment in the university such as the federal character and quota policy that warrants equal opportunities be accorded to regions in federal appointments and the fact that internet facilities are still not very common in some places where the supply of electricity is erratic

The relationship between separation and performance management system: The $\beta$ value $=0.14$, the tvalue $=0.27$ and $p$-value $=0.79$ led to the decision that this hypothesis is not supported in this study. This finding goes contrary to a number of literatures such as Beever (2008) and Rothwell et al. (2005). Looking at it from another perspective, Idris (2011) believed that the main reason behind lack of correlation between performance management and separation of employee is the in ability to prepare subordinates for the task ahead for lack of confidence in what the new leadership will signify in the future.

The relationship between separation and ICT adoption: This decision about this hypothesis is that it is supported in this study as shown in the values of $\beta=0.16$, $t$-value $=1.22$ and a $p$-value of 0.22 . This finding contradicts the researcher's expectation. It was found out that universities' inability to utilize ICT in procurement does not prevent them to monitor the development of their employees using ICT. The finding also concurs with the opinions of Sanayei and Mirzaei (2008) and Jaquenoud (2005) who stressed that organizations do adopt ICT to regulate employee separation via e-succession planning.

The relationship between ICT adoption and performance management: This study found that this hypothesis is supported as shown in the values of $\beta=0.09$, $t$-value $=0.20$ and $p$-value $=0.21$. The outcome of this study further supports those of Remus (2007) and Namazie and Frame (2007) who concluded that ICT is strong factor that assures employee performance management. Similar conclusions were also reached by Ruel et al. (2004) who added that ICT is very necessary for organizational progress which could not be attained without appropriate employee performance management.

\section{Conclusion}

It has been proven in this study that ICT adoption helps a lot in ensuring effective employee performance management system in Nigerian universities. It therefore remains a challenge for the government to ensure adequate funding of the universities which will no doubt have multiplier effects of reviving the education sector, ensure production of quality graduates, providing ample employment opportunities and above all salvaging the already troubled country's economy.

\section{References}

Baron, R. \& Kenny, D. (1986). The moderator-mediator variable distinction in social psychological research: conceptual, strategic, and statistical considerations. Journal of Personality and Social Psychology, 51 , 1173-82.

Bowles, S., Cunnigham, C. C. J. L., De La Rosa, G. \& Picano, J. (2007).Coaching leaders in middle and executive management: goals, performance, buy-in. Leadership \& Organization Development Journal, 28(5), 388-408

Beever, D. R. (2008). Integrating Succession and Career Development Strategies for Finance Professionals Victoria BC: Royal Roads University Canada.

Cedar, C. (2005). Workforce technologies and service delivery approaches survey, 8th Annual Edition. 
Chang, W. \& Chen, S. J. (2000). A study of the performance appraisal of the industrial designer in Taiwan. Journal of Technology, 15(3), 381-386

Chin, W. W., Marcolin, B. L. \& Newsted, P. N. (2003). A partial least squares latent variable modeling approach for measuring interaction effects: Results from a monte carlo simulation study and an electronic-mail emotion/adoption study. Information Systems Research, 14(2), 189-217.

Den Hartog, D. \& Verburg, R. (2004). High-performance work systems, organizational culture and firm effectiveness. Human Resource Management Journal, 14(1), 55-78.

Handlogten, C. (2009). Implementation of e-recruitment. Amsterdam: Universiteit Twente.

Heinen, J. S. \& O'Neill, C. (2004). Managing talent to maximize performance. Employment Relations Today, $31(2), 67-82$.

Holton, E. \& Trot, K. (2006).Competing for the future. Harvard Business Review, 72, 122-128.

Huang, T. C. (2000). Are the human resource practices of effective firms distinctively different from those of poorly performing ones? Evidence from Taiwanese enterprises. International Journal of Human Resource Management, 11, 436-451

Hussain, Z., Wallace, J. \& Cornelius, N. (2007). The use and impact of human resource information systems on human resource management professionals. Information \& Management, 44(1) , $74-89$.

Ishizaka, A. \& Labib, A. (2011). Review of the main developments in the analytic hierarchy process. Expert Systems with Applications, 38(11), 14336-14345.

Idris, F. (2011). Total quality management (TQM) and sustainable company performances: examining the relationship in Malaysian firms. International Journal of Business and Society, 12(1), 31-52

Jaquenoud, L. (2005).How to maximize HR technology. Strategic HR Review, 5(1), 4.

Kim, S. (2005). Individual-Level Factors and Organizational Performance in Government Organizations. Journal of Public Administration Research \& Theory, 15(2), 245-261

Kock, N. (2013). Advanced mediating effects tests, multi-group analyses and measurement model assessments in PLS-based SEM. Laredo, TX: ScriptWarp Systems.

Meier, K. J. \& Hicklin, A. (2008). Employee turnover and organizational performance: A theoretical extension and test with public sector data. Journal of Public Administration Research and Theory, 18(4), 573-590

Moynihan, D. P. \& Landuyt, N. (2008). Explaining turnover intention in state government: Examining the roles of gender, life cycle, and loyalty. Review of Public Personnel Administration, 28, 120-143.

Namazie, P. \& Frame, P. (2007). Developments in Human Resource Management in Iran. International Journal of Human Resource Managemnt, 18(1), 159-171.

O'Neal, T. (2005). Evolving a Successful University-Based Incubator: Lessons Learned from the UCF Technology Incubator. Engineering Management Journal, 17(3), 11-25

Remus, U. (2007). Critical success factors for implementing enterprise portals: A comparison with ERP implementations. Business Process Management Journal, 15, 538-552.

Richard, O. C. \& Johnson, N. B. (2001). Understanding the impact of human resource diversity practices on firm performance. Journal of Management Issues, 13, 177-195.

Ringle, C., Wende, S. \& Will, A. (2005). SmartPLS 2.0 M3. Hamburg: University of Hamburg. Retrieved June $6^{\text {th }}$ 2013, from http://www.smartpls.de

Rothwell, W., Jackson, R., Knight, S. \& Lindholm, J. (2005). Career planning and succession management: Developing your organization's talent-for today and tomorrow. Westport, CT: Greenwood Press.

Ruël, H., Bondarouk, T. \& Looise, J. (2004). E-HRM: Innovation or Irritation. Utrecht: Lemma Publishers.

Sanayei, A. \& Mirzaei, A. (2008). Designing a Model for Evaluating the Effectiveness of e-HRM (Case Study: Iranian Organizations). International Journal of Information Science and Technology, 6(2).

Sodhi, M. S. \& Lee, S. (2007). An analysis of sources of risk in the consumer electronics industry. JORS, 58(11), 1430-1439

Stanton, J. M. \& Coovert, M. D. (2004). Turbulent waters: The intersection of information technology and human resources. Human Resource Management, 43(2), 121-125

Strohmeier, S. (2007). Research in e-HRM: Review and implications. Human Resource Management Review, 17, 19-37.

Tabachnick, B. G. \& Fidell, L. S. (2007). Using multivariate statistics (5th ed.). Boston: Pearson Education Inc.

Townsend, A. M. \& Bennett, J. T. (2003). Human resources and information technology. Journal of Labor Research, 24(3), 361-363 
Tzafrir, S. S. (2006). An universalistic perspective for explaining the relationship between HRM practices and firm performance at different points in time. Journal of Managerial Psychology, 21(2), 109-130

Viswesvaran, C. (2003). Introduction to special issue: Role of technology in shaping the future of staffing and assessment. International Journal of Selection and Assessment, 11(2/3), 107-112

Williams, H. (2010). The HRIS specialist: Resourcing the "right kind" of human capital. In S. Strohmeier \& A. Diederichsen (Eds.), Evidence-based e-HRM? On the way to rigorous and relevant research, Proceedings of the 3rd European academic workshop on electronic human resource management, Bamberg.

Yusoff, Y. M., Ramayah, T. \& Ibrahim, H. (2010). E-HRM: A proposed model based on technology acceptance model. African Journal of Business Management, 4(13), 3039-3045. 